\title{
FORMAÇÃO PROFISSIONAL E PRÁTICA SUSTENTÁVEL
}

\section{1- João Carlos da Cunha*}

Doutor em Administração pela Universidade de São Paulo (USP), Brasil.

Professor do Programa de Pós-Graduação em Administração da Universidade Federal do Paraná (PPGADM/UFPR), Brasil. jccunha@ufpr.br

http://lattes.cnpq.br/6500765563409109

\section{2- Ludmilla Meyer Montenegro}

Doutora em Administração pela Universidade Federal do Paraná (UFPR), Brasil.

Professora da Universidade Federal de Sergipe (UFS), Brasil.

ludmilla2907@gmail.com

http://lattes.cnpq.br/8407082004742006

\section{3- Natália Rese}

Doutora em Administração pela Universidade Federal do Paraná (UFPR), Brasil.

Professora do Programa de Pós-Graduação em Administração da Universidade Federal do Paraná (PPGADM/UFPR), Brasil. resenati@gmail.com

http://lattes.cnpq.br/2021488454855419

\section{4- Simone Crocetti}

Doutora em Administração pela Universidade Federal do Paraná (UFPR), Brasil.

Professora da Universidade Tecnológica Federal do Paraná (UTFPR), Brasil.

simonecrocetti@gmail.com

http://lattes.cnpq.br/9711137830945675

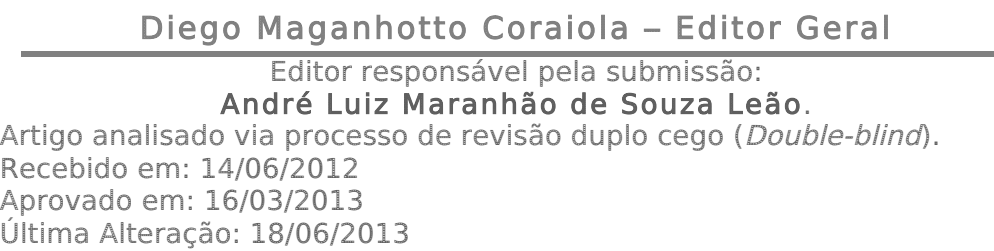

* Contato Principal: Av. Pref. Lothario Meissner, 632 2a andar - Jardim Botânico - CEP: 80210-170 Curitiba-PR. 


\section{FORMAÇÃO PROFISSIONAL E PRÁTICA SUSTENTÁVEL}

\section{RESUMO}

O objetivo deste estudo é a discussão de ideias para a formação de profissionais comprometidos com a prática sustentável, visto que o conceito de sustentabilidade tem sido utilizado de forma constante nas empresas. A pesquisa é qualitativa, de natureza exploratória, e utilizou como método o estudo de três casos em um Instituto Federal de Ensino Superior, situado no estado do Paraná. A análise dos dados baseou-se nos princípios do paradigma e do modelo condicional/consequencial da grounded theory. Os resultados indicam que a adoção do conceito de sustentabilidade na prática profissional é um processo ainda em construção, uma vez que se percebeu pouco ou nenhum comprometimento com o conceito de sustentabilidade nos casos estudados. As conclusões indicam que: (1) os estudantes não têm claro o conceito de sustentabilidade; (2) a construção da noção de sustentabilidade como prática social tem um caminho relevante a ser trilhado; e (3) a sociedade precisa incorporar efetivamente a sustentabilidade como noção importante.

Palavras-chave: Sustentabilidade, prática social, ensino, formação profissional, educação sustentável.

\section{PROFESSIONAL QUALIFICATION AND SUSTAINABLE PRACTICES}

\section{ABSTRACT}

The aim of this paper is the discussion of ideas related to the qualification of professionals committed with the sustainable practice, because the sustainability concept has been constantly used in the firms. It is an explorative qualitative study and the method used was the study of three cases in a Federal Institution of Higher Education at Paraná state. The data analysis was based on the principles of the paradigm and the conditional/consequential model of the grounded theory. The results indicate that the adoption of the sustainability concept in the professional practice is still a process in construction, due to the fact that there is little or almost no commitment with this concept in the studied cases. Some conclusions: (1) the students do not have a clear idea of what the sustainability concept means; (2) the construction of the sustainability notion as a social practice has a relevant path to be developed; and (3) the society needs to incorporate, effectively, the sustainability as an important notion.

Keywords: Sustainability, social practice, teaching, professional qualification, sustainable education. 


\section{Introdução}

Sustentabilidade é um conceito que está, cada vez mais, sendo utilizado em diversas áreas de conhecimento. Às vezes, é utilizado de forma apropriada, outras vezes, percebe-se falta de clareza e de discernimento sobre a definição e a utilização do conceito. Diante dessas questões, observa-se que, além da ambiguidade que permeia o termo, há ainda uma dificuldade por parte de professores, alunos, pesquisadores e empresários de compreender essa questão no âmbito das atividades e práticas cotidianas empreendidas. Notase a necessidade de se compreender o que são e como se dão as práticas sustentáveis.

Acredita-se que um estudo que busque compreender a formação profissional voltada para a prática sustentável, explorando a abordagem da prática social, seja um caminho para começar a entender essas questões que se apresentam como incipientes, visto serem poucas as pesquisas que abordam o tema. Além das pesquisas abordadas no referencial teórico, há as desenvolvidas por Fortuin e Bush (2010), Sipos, Battisti e Grimm (2008) e Stubbs e Cocklin (2008).

Mais especificamente, o tema proposto pauta-se no entendimento de que a sustentabilidade deve ser compreendida como prática social, o que significa que é construída pelos sujeitos em interação social, que permanece e é disseminada por meio dessas ações que sustentam a realidade social. Consequentemente, para que se consiga a formação de profissionais comprometidos com a sustentabilidade, é necessário refletir sobre os meios possíveis para a formação desses sujeitos, de forma que estejam comprometidos com a noção de prática social.

Com o intuito de contribuir para esse panorama que se apresenta, este trabalho tem como objetivo identificar as práticas de ensino que contribuem para a formação de profissionais comprometidos com a sustentabilidade. Para isso, são empreendidas algumas ações investigativas: (1) desenvolver as ligações conceituais entre sustentabilidade e prática social; (2) levantar as práticas educacionais compatíveis com a formação voltada para a sustentabilidade; (3) identificar, a partir da consulta com especialistas, as práticas de ensino-aprendizagem recorrentes no campo estudado; e (4) traçar ideias para um possível padrão da formação profissional para a sustentabilidade.

Este trabalho está dividido nas seguintes seções: primeiro, é apresentada esta introdução. Segundo, é delineado o referencial teórico que se subdivide em desenvolvimento sustentável, educação sustentável e noção de prática social como fio condutor para um profissional sustentável. Terceiro, é apresentada a metodologia do trabalho seguida pela análise dos dados. Por fim, são apresentadas as considerações finais e as referências bibliográficas.

\section{Referencial Teórico}

Inicialmente serão apresentados os conceitos de sustentabilidade. Na sequência, faz-se relevante compreender os conceitos de educação sustentável. Por fim, será contextualizada essa educação à luz das teorias de prática social.

\subsection{Sustentabilidade}

O desenvolvimento sustentável foi definido pelo Relatório Brundtland como um modelo voltado ao "atendimento das necessidades do presente sem comprometer a capacidade de as gerações futuras satisfazerem suas próprias necessidades" (Comissão Mundial Sobre Meio Ambiente e Desenvolvimento, 1991). Na mesma linha, Meadows, Meadows e Rangers (1992) afirmam que sociedade sustentável é aquela que pode persistir ao longo das gerações, por enxergar distante, ser flexível e sábia o suficiente para não deteriorar seus próprios sistemas físicos e sociais de suporte. Blackburn (2007) indica que a sustentabilidade precisa considerar o uso e a gestão de recursos de forma razoável e o respeito pelas pessoas e outros seres vivos. A implantação dessa lógica leva às organizações uma perspectiva de longo prazo de bem-estar, válida também para a sociedade.

São verificadas algumas barreiras para a efetiva adoção da sustentabilidade. Uma das barreiras, segundo Carrilo-Hermosilla, González e Könnölä (2009), acontece com as empresas que desenvolvem inovações sustentáveis, por meio de investimento em pesquisa e desenvolvimento, porém são rapidamente superadas pelas demais, que apenas reproduzem as práticas sustentáveis. Outra barreira é que, algumas vezes, a redução da pressão no meio ambiente não é rapidamente traduzida em redução de custos, não sendo os benefícios sociais facilmente transformados em vantagens para os empreendimentos. A essas barreiras financeiras, somase a tendência em seguir com soluções antigas, seja pela familiaridade, ou pelo medo da novidade. Isso é denominado de trava tecnológica e institucional.

Conhecendo as barreiras, Blackburn (2007) propõe um modelo para a implementação da sustentabilidade dentro das empresas. O ponto principal é a análise crítica dos comportamentos sustentáveis esperados, que resultará em políticas da empresa formalmente definidas. Nessa busca pela absorção da sustentabilidade como valor da empresa, é importante considerar que devem ser estabelecidos objetivos internos e externos para cada um dos itens da sustentabilidade (econômico, meio ambiente e social). Além disso, os objetivos precisam permear toda a empresa para que todos estejam de alguma forma envolvidos na transformação. 
Segundo resultados de pesquisas empíricas apresentadas por Carrilo-Hermosilla, González e Könnölä (2009), quando as empresas investem no aprimoramento das capacidades tecnológicas, por meio de maior nível educacional de seus profissionais, elas colhem como consequência a inovação sustentável, um dos componentes do comportamento sustentável. Esse aprimoramento aumenta o aprendizado organizacional e o fluxo de informações de forma a possibilitar o desenvolvimento de inovações sustentáveis, bem como implementar esse pensamento dentro dos processos de produção já implantados.

\subsection{Educação Sustentável}

Diante de discussões recorrentes, como, por exemplo, as de Barbieri (2011) e Hart (2006), sobre o tema sustentabilidade, é comum observar uma preocupação com a questão da conscientização, ponto que parece ser a etapa inicial e essencial para qualquer mudança e desenvolvimento no que se refere ao assunto no âmbito da educação. É importante que os envolvidos compreendam o conceito de sustentabilidade e entendam a importância de adotar posturas sustentáveis em uma universidade sustentável ou um curso sustentável (ou que se preocupa profundamente com essas questões).

Para Weenen (2000), algumas mudanças são inevitáveis. O autor acredita que áreas como administração, pesquisa, educação, comunicação e operações de qualquer universidade com um interesse genuíno em desenvolvimento sustentável terão que mudar. Sabe-se que essas mudanças não serão facilmente adotadas, visto já existirem padrões de "insustentabilidade" arraigados nessas instituições. A forma como essas mudanças serão implementadas são variadas. Estudos indicam que a fase de conscientização seria uma possível base para as fases seguintes por ser bastante relevante no processo de mudanças.

Para Shriberg (2002), antes da implantação da sustentabilidade nos currículos dos cursos de graduação, faz-se necessária sua efetivação na forma de agir da própria universidade. Para tanto, questões referentes à quantidade de material consumido, estratégia e política de atuação da universidade, formatação dos currículos atuais, participação e envolvimento da universidade em projetos da comunidade, além do comportamento dos graduandos frente ao mundo, precisam ser investigadas. A partir deste diagnóstico da situação vigente, planos e metas podem ser estabelecidos, de forma a viabilizar as mudanças necessárias no ambiente universitário, culminando com a assimilação dos preceitos da sustentabilidade tanto nos conteúdos ministrados como no formato das universidades.

Segundo Marshall e Harry (2005), ensinar conteúdos sob o prisma da sustentabilidade consiste em manter as práticas de ensino correntes, ou seja, mostrar as ligações entre entradas e ações com produtos e resultados. Porém com uma diferença central, a inclusão de novas variáveis que tornam o sistema mais complexo, em que as decisões passam também a considerar perspectivas políticas, tecnológicas, econômicas, sociais e ambientais. Neste novo contexto, ao solucionar um problema, o estudante precisa verificar particularidades e desafios apresentados por uma região, além dos métodos (sustentáveis ou não) já utilizados anteriormente para resolver questões parecidas e, a partir daí, propor uma nova solução.

Outra questão no trabalho da sustentabilidade na educação é a transparência. É importante que todos os envolvidos com a universidade saibam o que está acontecendo: quais mudanças serão implementadas, por que serão implementadas, quem serão as pessoas envolvidas com as mudanças e, principalmente, quais os resultados esperados. Diante disso, preza-se pela organização e disseminação das informações. Consequentemente, a questão das redes também aparece como importante. Não somente as redes de colaboração, mas também as de contatos, em que grupos estão numa constante troca de informações. As informações são lançadas diariamente e os acessos a essas atualizações também devem ser diários (Weenen, 2000).

Um exemplo interessante é o da Ithaca College (IC). Eles decidiram desenvolver uma matriz curricular em Estudos Ambientais. Optou-se por elaborar algo focado, pois acreditavam que a multidisciplinaridade, inerente a muitos cursos de graduação, geralmente, dificulta o desenvolvimento de uma matriz curricular condizente com uma boa formação em determinada área do conhecimento. A matriz curricular de Estudos Ambientais desenvolvida abrange aspectos bem-sucedidos de outros programas e sugestões de críticos da área. A grande inovação diz respeito ao desenvolvimento de uma parceria com a comunidade, mais especificamente, com um modelo local sobre sustentabilidade ambiental criado por essa comunidade. A sugestão foi dada pela Universidade Estadual da Pensilvânia: combinar matriz curricular com afiliação comunitária (Allen-Gil, Walker, Thomas, Shevory, \& Elan, 2005).

A thaca College fez uma adaptação à sua realidade, e alguns objetivos foram traçados. É importante destacar o cuidado e o empenho empreendidos no desenvolvimento do curso, o interesse de ambas as partes (universidade e comunidade) e o envolvimento de todos. Outro ponto importante levado em consideração foi a metodologia utilizada nas disciplinas do curso focado em desenvolvimento de projetos, demonstrando preocupação com a relação teoria e prática. Ao final, os envolvidos perceberam que essa aproximação/colaboração universidade-comunidade foi algo positivo, pois a noção de sustentabilidade se tornou clara para todos (Allen-Gil et al., 2005).

Weenen (2000) e Allen-Gil et al. (2005) sugerem que, em cursos relacionados à sustentabilidade, o professor deve sempre buscar atividades que associem a teoria com a prática e que levem o aluno a vivenciar questões da prática através do desenvolvimento de projetos, por exemplo. Para Warburton (2003), uma educação efetiva para a sustentabilidade deve fazer com que o aluno reflita sobre sua aprendizagem e o leve às mudanças de valores, atitudes e comportamentos. Para esse autor, os alunos devem ser informados a respeito 
de questões ambientais e cuidados que devem tomar e também desenvolver a habilidade de análise e investigação, aprender sobre estratégias efetivas para lidar com problemas e desenvolver uma compreensão aprofundada de conceitos-chave. Segundo Grauerholz (2001), aprendizagem profunda ocorre quando é ao mesmo tempo emocional e intelectual, física e mental, social e pessoal, totalmente única, ainda que livremente compartilhada.

É importante destacar que essa aprendizagem aprofundada, sugerida por Warburton (2003), pode ser algo difícil para alguns alunos, pois exige que se cruzem os limites das disciplinas com certa regularidade. Os estudantes terão sempre que ter em mente questões científicas e de humanidades, porquanto não existe essa separação na sustentabilidade. Portanto, entende-se que o desafio para as instituições educacionais não é simplesmente ensinar fatos concretos sobre o meio ambiente, e sim criar um processo de aprendizagem ativo e transformativo que permita que os valores sejam vividos e debatidos, unificando teoria com a prática (Warburton, 2003). Essa perspectiva parece corroborar a perspectiva de entendimento da sustentabilidade como prática social, uma vez que evidencia questões relacionadas à vivência e à aproximação (ou não dissociação) da teoria com a prática.

Por fim, convém mencionar algumas boas práticas trabalhadas em alguns cursos de sustentabilidade destacadas por Henze (2000, p. 284):

- Interdisciplinaridade: Existem palestras direcionadas ao objetivo da cooperação interdisciplinar, que promovem a ideia e a prática da cooperação interdisciplinar e interdepartamental.

- Aprendizagem global: Essa premissa didática é preenchida por cursos que lidam com experiência ambiental local, problemas individuais e soluções de problemas com resultados possíveis em desenvolvimento global. Na disciplina Geografia, por exemplo, isso pode ser alcançado pela ligação entre temas locais com temais mundiais. O objetivo é preparar-se para a parceria global e para a cooperação internacional e intercultural.

- Conectando educação no nível da universidade com escolas e comunidades: Os dados indicam que existem alguns esforços em universidades para conectar treinamento terciário com o campo profissional futuro da escola. Na Universidade de Duisburg e na Universidade de Bochum, por exemplo, departamentos individuais estão ativamente envolvidos em processos da agenda local. Em outros institutos, departamentos individuais cooperam com escolas. Dessa forma, alunos familiarizam-se com os trabalhos das escolas e com formas inovadoras de aprendizagem de forma prática e ativa.

- Desenvolvimento de competência reflexiva e comunicativa: Esse critério é focado explicitamente nos meios prospectivos de ensino e aprendizagem. A questão interessante é como estudantes, passo a passo, podem ser introduzidos em formas de participação, em processos de aprendizagem independentes e auto-organizados, no desenvolvimento de iniciativas e responsabilidade, no diálogo e na aprendizagem crítica. É importante ressaltar que o princípio da auto-organização é avaliado positivamente dentro do conceito de desenvolvimento sustentável.

Com base no que foi discutido até o momento, observa-se que entender a sustentabilidade como uma prática social é algo que já é realidade em algumas instituições. As pessoas envolvidas vivenciam questões de sustentabilidade na prática, teorizam sobre isso e desenvolvem atividades do dia a dia que refletem questões práticas e teóricas. A sustentabilidade já é algo natural para elas, algo vivenciado em seus cotidianos (Henze, 2000; Allen-Gil et al., 2005).

\subsection{A Noção de Prática Social como Fio Condutor para um Profissional Sustentável}

Desde os anos 80, tem-se observado uma "virada prática" na teoria social contemporânea, a partir da qual autores como Pierre Bourdieu, Michel De Certeau, Michel Foucault e Anthony Giddens passaram a recuperar e pensar sobre a prática e sua importância na teoria social (Whittington, 2006; Johnson, Langley, Melin, \& Whittington, 2007).

A noção de prática social enfatiza as microatividades situadas, rotinizadas e também os meios de fazer as coisas que possibilitam a realização da vida cotidiana. Nesse sentido, entende-se que, apesar das regras, das instituições, dos discursos que condicionam a vida em sociedade, existe o espaço da criação, do fazer acontecer, da realização da vida cotidiana e é nesse espaço que ocorrem resistência àquilo que é imposto como discurso dominante e a criação da mudança que permite efetivamente que as atividades sejam realizadas (Certeau, 1984, 1994; La Ville \& Monoud, 2003).

Neste ínterim, a linguagem e a produção dos sentidos ganham espaço, entendendo-se que:

para os membros da organização interagirem, eles precisam construir uma linguagem compartilhada, materializada em um texto, propiciando que eles cooperem. Isso começa nas conversações diárias, com a interação mútua, o que é um prerrequisito para a atividade organizada. Os textos narrativos resultantes são produções secundárias que formalizam as interpretações construídas nas conversações e as transportam para as futuras ações. Os textos produzidos não só retêm os traços das conversações originais, mas também modelam as ações subsequentes, oferecendo modelos interpretativos para dar sentido aos eventos em andamento (La Ville \& Mounoud, 2006, p. 5). 
Entende-se assim que existe espaço para os discursos dominantes (estruturantes e que conferem bases para ação) e para a interpretação desses discursos por parte das pessoas (a ação), abrindo espaço para a resistência e para a construção criativa (Giddens, 2003; Certeau, 1984).

A noção de práticas sociais propicia, portanto, o entendimento da importância da prática, da realização das atividades, juntamente com o planejamento. Retoma-se a noção de que o fazer é importante, contrariando a noção da supremacia do pensar sobre o fazer, uma vez que a estrutura social é mantida e perpetuada por essas práticas (Whittington, 2002, 2006).

Considerando a noção de sustentabilidade que tem tomado a mídia, os discursos empresariais e a sociedade como um todo, percebe-se que, até o momento, essa noção tem figurado no campo discursivo como discurso dominante e dentro da noção de "estratégia" de Certeau (1984), privilegiando-se o "pensar" em detrimento do "fazer". Ainda são poucas a ações efetivas no campo das organizações para o alcance da sustentabilidade, como apontaram as pesquisas, por exemplo, de Padilha (2009) e Scandelari e Cunha (2011). Adicionalmente, surgem questionamentos sobre como transformar os conceitos em ação, entendendo-se, muitas vezes, que isso passa pelo processo educativo de jovens e profissionais, capazes de imprimir um caráter sustentável às suas práticas. O “como" fazer uma educação sustentável tem sido bastante discutido também.

Partindo disso, entende-se que tomar a noção de práticas sociais como fio condutor para a concepção de uma educação para a sustentabilidade, na formação profissional, constitui-se na possibilidade de ultrapassar a dimensão do "pensar" para a do "fazer". Tomar os grandes discursos, as "estratégias" da sustentabilidade e transformá-los em narrativas, nas “táticas” de Certeau (1984), parece um caminho capaz de levar à formação para a sustentabilidade.

\section{Metodologia}

Foi utilizada metodologia qualitativa de natureza exploratória, que se caracteriza pela investigação de um tema (práticas sociais), pautada em novas perspectivas (aplicadas em sala de aula, que incentivem a sustentabilidade), visando a ampliar estudos já existentes (práticas sociais, educação e sustentabilidade), considerando os diversos atores que contribuem para o processo (Sampieri, Collado, \& Lucio, 2006).

O método aplicado foi o estudo de casos múltiplos incorporados, do tipo holístico (Yin, 2001), possibilitando compreender áreas contrastantes. Inicialmente, o estudo de casos teve visão incorporada, ou seja, a investigação foi realizada em cursos e projeto de extensão; na sequência, esses casos foram analisados à luz do contexto da sociedade e da universidade, caracterizando uma visão holística.

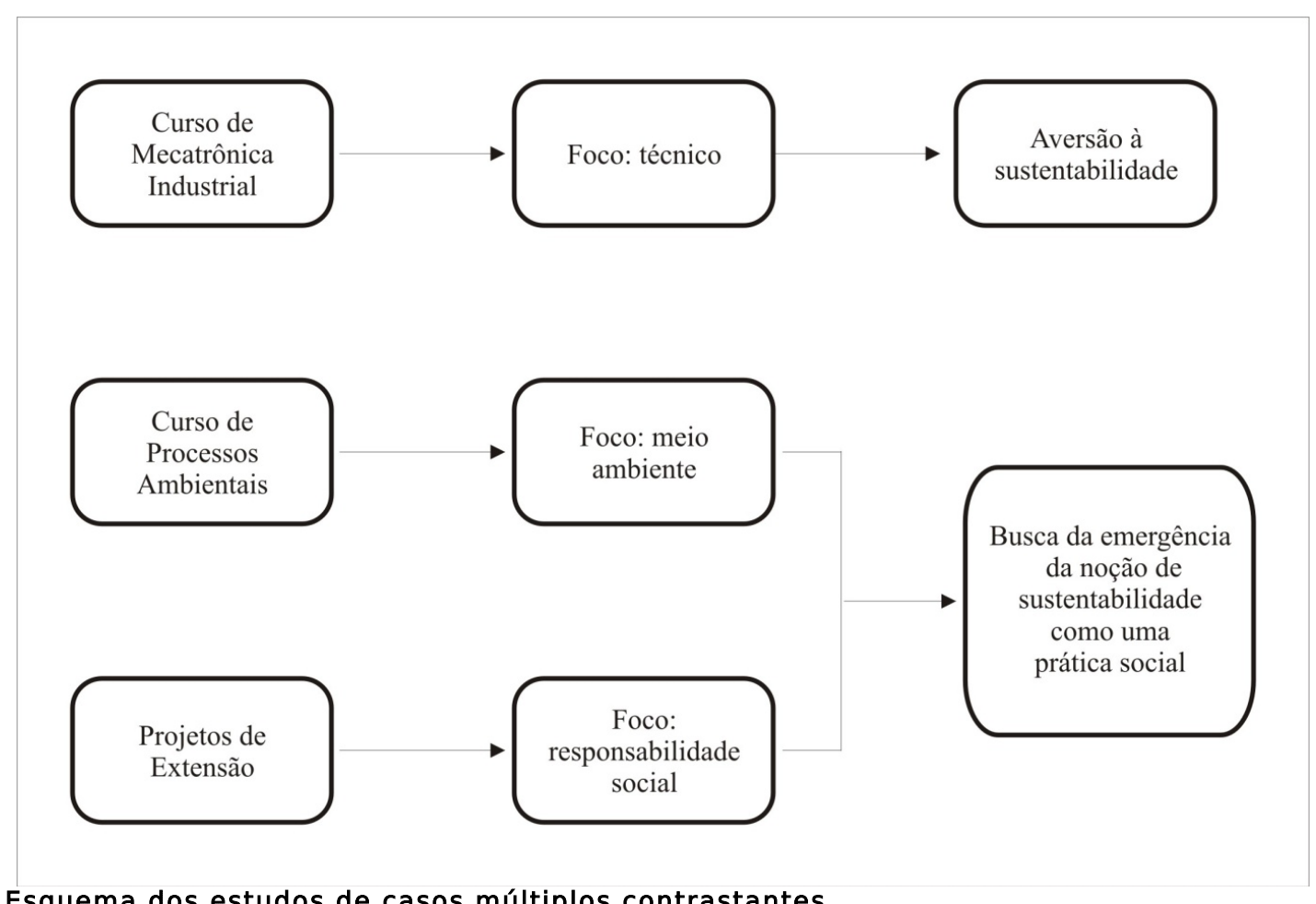

Figura 1 - Esquema dos estudos de casos múltiplos contrastantes

Fonte: Elaborada pelos autores.

Os dados foram colhidos apenas uma vez, caracterizando perspectiva temporal transversal. A unidade de análise são as práticas sociais percebidas no nível das aulas ou das atividades dos projetos de extensão. Como - IFES (Instituto Federal de Ensino Superior) pesquisado oferece mais de 80 cursos de graduação e pósgraduação, foram selecionados casos de cursos e projeto de extensão para que os pesquisadores tivessem acesso a dados primários e secundários. A sustentabilidade, na área de administração, permeia os discursos 
gerenciais e as estratégias de ação. No entanto, como se defende nessa pesquisa, a passagem do “discurso para a narrativa" (La Ville \& Mounoud, 2003) é fundamental para que a sustentabilidade se consolide como prática social. Essa “passagem” depende da interface com os profissionais das áreas técnicas, visto estarem envolvidos com o cotidiano organizacional. Consequentemente, foram pesquisados os cursos de Mecatrônica, Processos Ambientais, bem como um projeto de extensão do IFES relacionado ao desenvolvimento sustentável da comunidade.

Em um dos casos, foi observada uma aversão à noção de sustentabilidade, enquanto no outro há um esforço em implantar ações que busquem a emergência da noção de sustentabilidade como uma prática social. Nas atividades de extensão, foi observado foco em responsabilidade social, enquanto no curso de Processos Ambientais, o foco é o meio ambiente. A configuração dos casos está esquematizada na Figura 1.

A coleta de dados ocorreu por meio de fontes primárias e secundárias. Os dados primários foram obtidos em entrevistas semiestruturadas com professores e estudantes, juntamente com observação não participante nas aulas. Os dados secundários foram obtidos em documentos disponíveis no site do IFES como projeto de desenvolvimento institucional (PDI), caracterização dos cursos e currículo Lattes dos professores. Adicionalmente, para complementar as teorias estudadas para a realização desta pesquisa, foi entrevistada uma pesquisadora que estuda educação e sustentabilidade. Na Figura 2, está a compilação das fontes de dados.

\begin{tabular}{|l|l|l|}
\hline \multicolumn{1}{|c|}{ Caso } & \multicolumn{1}{|c|}{ Dados primários } & \multicolumn{1}{c|}{ Dados secundários } \\
\hline \hline Curso de Mecatrônica & $\begin{array}{l}\text { Entrevistas com dois professores, quatro estudantes } \\
\text { e a coordenadora; e } \\
\text { Observação não participante em aulas. }\end{array}$ & $\begin{array}{l}\text { Currículo Lattes; e } \\
\text { Descrição do curso. }\end{array}$ \\
\hline $\begin{array}{l}\text { Curso de Processos } \\
\text { Ambientais }\end{array}$ & $\begin{array}{l}\text { Entrevistas com três professoras e um estudante; e } \\
\text { Observação não participante em aulas. }\end{array}$ & $\begin{array}{l}\text { Currículo Lattes; e } \\
\text { Descrição do curso. }\end{array}$ \\
\hline Projeto de extensão & $\begin{array}{l}\text { Entrevistas com um professor coordenador e dois } \\
\text { estudantes bolsistas. }\end{array}$ & $\begin{array}{l}\text { Currículo Lattes; e } \\
\text { Relatórios das atividades de extensão. }\end{array}$ \\
\hline
\end{tabular}

\section{Figura 2 - Fontes de dados}

Fonte: Elaborada pelos autores.

Por entender que as aulas/extensão e as práticas sociais são resultado da combinação com o contexto em que estão inseridas, os dados foram analisados por meio dos princípios do paradigma e do modelo condicional/consequencial recomendados por Strauss e Corbin (2008) e estão esquematizados nas Figuras 3 e 4.

\begin{tabular}{|l|l|}
\hline \multicolumn{1}{|c|}{ Fatores } & \multicolumn{1}{c|}{ Delimitação para a pesquisa } \\
\hline \hline Estrutura & $\begin{array}{l}\text { Sociedade, IFES, projeto dos cursos e da atividade de extensão, professores, estudantes e } \\
\text { aulas. }\end{array}$ \\
\hline Processo & Análise a partir da sociedade até chegar às aulas e, dessas, retornando até a sociedade. \\
\hline Condições & Circunstâncias oferecidas pela estrutura e processo para as aulas e projeto de extensão. \\
\hline Ações/interações & Aulas e atividades de extensão. \\
\hline Consequências & Possíveis alterações na estrutura e processo a partir das aulas e projeto de extensão. \\
\hline Contexto & Condições e consequências. \\
\hline $\begin{array}{l}\text { Condições e consequências } \\
\text { micro }\end{array}$ & Professores e estudantes. \\
\hline $\begin{array}{l}\text { Condições e consequências } \\
\text { macro }\end{array}$ & Sociedade, IFES e projeto dos cursos e da atividade de extensão. \\
\hline
\end{tabular}

Figura 3 - Delimitação dos fatores do paradigma e modelo condicional/consequencial

Fonte: Elaborada pelos autores.

O uso dos princípios do paradigma, proposto por Strauss e Corbin (2008), permite captar a dinâmica e a complexidade da estrutura e do processo, que estão intrinsecamente ligados. A estrutura resulta do contexto condicional, no qual um fenômeno (nesta pesquisa: ações que buscam a emergência da noção de sustentabilidade como uma prática social) está situado. O processo é a sequência de ações/interações pertencentes a um fenômeno, à medida que se desenvolvem com o tempo. Os componentes do paradigma são: (1) condições, (2) ações/interações e (3) consequências. As condições são os conjuntos de circunstâncias nos quais os fenômenos estão incorporados e, até certo ponto, explicam por que e como pessoas ou grupos respondem de determinadas maneiras. As ações/interações são atos deliberados praticados para resolver um 
problema. As consequências são o resultado das ações/interações ou mesmo da falta delas. Finalmente, da combinação entre as condições e as consequências emerge o contexto.

Contudo, Strauss e Corbin (2008) alertam que a utilização apenas dos princípios do paradigma tornam a análise incompleta. Para estimular o pensamento sobre as relações entre condições e consequências micro e macro, uma com a outra e com o processo, recomenda-se a utilização do modelo condicional/consequencial. Esse modelo permite localizar os fenômenos dentro de um escopo completo de condições macro e micro, no qual ele está inserido e acompanhar as relações de ações/interações por meio de suas consequências.

A pesquisa, por ser exploratória, não pretendeu comprovar ou refutar determinada teoria, mas buscar subsídios que permitam a compreensão da prática social e do ensino da sustentabilidade. A escolha metodológica impossibilita a generalização estatística, uma vez que o método adotado foi o estudo de três casos. Os cursos estudados são da área técnica, sendo uma limitação da pesquisa, porque não teve foco na área de Administração, mas é também uma oportunidade para estudos futuros, conforme será citado nas considerações finais deste artigo.

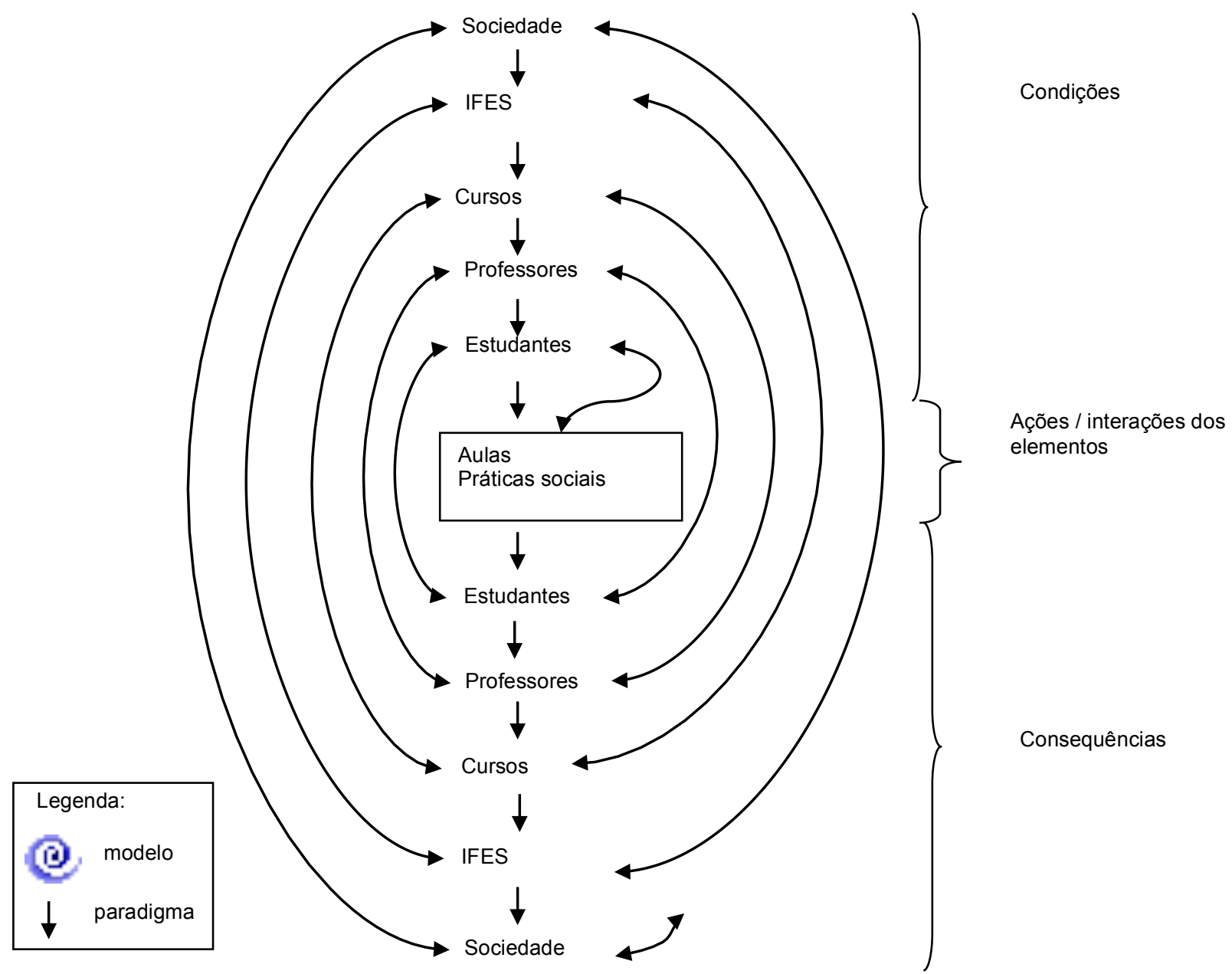

Figura 4 - Modelo condicional/consequencial e princípios do paradigma Fonte: Elaborada pelos autores com base na adequação dos procedimentos recomendados por Strauss e Corbin (2008).

\subsection{Descrição dos Dados}

Ao serem questionados sobre as práticas de ensino que desenvolvem, os professores do curso de Mecatrônica apontaram não ter a preocupação com a inserção do tema sustentabilidade em suas disciplinas. Em busca de entender o porquê desse fato, perguntou-se a eles o motivo pelo qual não abordavam a sustentabilidade como tema - específico ou transversal - em suas disciplinas. As principais respostas foram: (1) a efemeridade do tema, visto que, para eles, o tema sustentabilidade é um modismo e não tem sustentação teórica e/ou prática; (2) o desinteresse pela questão, que faz com que não a investiguem em suas pesquisas e, portanto, não reflitam isso em sua prática de sala de aula; e (3) a falta de relevância em sala de aula, porque, para alguns professores, a sustentabilidade é compreendida, basicamente, como relevante apenas para assuntos econômicos, logo, não seria relevante nas práticas de ensino.

Outra questão a ser destacada é o entendimento que os entrevistados, em geral, possuem acerca da sustentabilidade: tanto professores quanto alunos não apresentam uma definição clara e precisa para o termo. Alguns citam a dimensão ecológica/ambiental, outros a dimensão econômica e raramente a dimensão social é 
trabalhada. Além disso, tratar as dimensões a partir da sua dinâmica e inter-relações é um aspecto que não foi identificado nas evidências levantadas.

Especificamente, os alunos do curso de Mecatrônica, que estão em fase final do curso, quando perguntados se perceberam, ao longo da sua trajetória de ensino na instituição, a preocupação com a sustentabilidade durante as aulas, apontaram que o tema não é abordado especificamente e nem transversalmente. Dessa forma, a sustentabilidade não é uma preocupação presente na formação acadêmica dos estudantes, nem na sua prática profissional, visto que eles citam o tema como pouco impactante nas empresas em que trabalham.

Percebe-se que não há evidências de práticas sustentáveis nesse curso (nem nos projetos desenvolvidos pelos alunos). Mesmo que eles, em algum momento, utilizem materiais descartados, que estão sendo reaproveitados, e, com essa ação, de certa forma, ajudem o meio ambiente, não se configura como prática social, pois essa ação não é algo que eles reconheçam como sustentabilidade, nem é algo compartilhado e feito de forma natural no cotidiano deles.

Os professores do curso de Processos Ambientais e o professor do projeto de extensão - que desenvolvem atividades, trabalhos e práticas pedagógicas - estão preocupados com questões sociais, econômicas e ambientais e, consequentemente, estão caminhando para a construção de um pensamento sustentável para chegar ao desenvolvimento de práticas sustentáveis efetivas. Para esses professores, a sustentabilidade é importante e deve ser levada em consideração não apenas em sala de aula, mas no dia a dia dos alunos e professores.

Percebe-se um esforço por parte desse grupo de professores para empreender ações relacionadas às práticas sustentáveis. Alguns alunos do curso possuem predisposição para esse tipo de abordagem e se integram com maior facilidade. Algumas práticas já estão sendo desenvolvidas pelos professores do curso de Processos Ambientais e pelo professor do projeto de extensão; porém, ainda são incipientes (familiarização com os conceitos, aprendizado de formas de exposição do tema sustentabilidade, por exemplo), já outras estão um pouco mais elaboradas, mesmo que, a priori, sejam localizadas e pontuais.

Observa-se que cada professor do curso de Processos Ambientais e do projeto de extensão apresenta uma maneira particular de disseminar, incorporar e se apropriar das práticas sustentáveis. Alguns preferem trabalhar essas questões fortemente em sala de aula, para esse professor, a sustentabilidade pode e deve ser ensinada por meio de práticas pedagógicas. Eles veem a sala de aula como o local adequado para isso. Outros professores optam por trabalhar práticas sustentáveis mais na pesquisa e na extensão, o que acontece, muitas vezes, de forma associada. O aluno vai a campo, conhece uma comunidade, por exemplo, intervém (na forma de projeto de extensão) e transpõe os dados para suas pesquisas de iniciação científica e de mestrado. Percebe-se, então, que cada profissional busca a forma com a qual se sente mais à vontade para tratar do tema. Destaca-se que a visão de administrador do coordenador do projeto de extensão mostrou-se facilitadora para a disseminação do conceito de sustentabilidade, pela compreensão aprofundada do tema e pela capacidade de traduzir os conceitos e, com isso, envolver os participantes, que são de diversas áreas tecnológicas. Convém lembrar que não cabe o julgamento de qual é a forma mais adequada e/ou se uma é melhor que a outra, mas saber se os resultados dessas ações são positivos.

Quando os especialistas em educação são questionados para a sustentabilidade, há o entendimento de que a clareza conceitual e a vivência do tema nas práticas educacionais são fundamentais. Para que a formação de estudantes esteja alicerçada na prática sustentável, é preciso que todo o desenho das disciplinas, do currículo e das aulas esteja vinculado ao entendimento da sustentabilidade, que deve ser tratado, constantemente, como conhecimento específico e transversal. Ao mesmo tempo, é preciso trabalhá-lo na vivência da sala de aula, em desenvolvimento de projetos, visitas técnicas, desenvolvimento de soluções interdisciplinares e que isso esteja vinculado ao contexto socioambiental e econômico. Para isso, é necessário que as áreas de ensino, pesquisa e extensão estejam fortemente conectadas e em constante relacionamento.

Partindo da lógica descrita acima pelos especialistas em educação para a sustentabilidade, percebe-se a necessidade de o conceito da sustentabilidade ser elevado ao status de prática social, em que os atores sejam capazes de rotinizá-lo e trabalhá-lo em todas as atividades cotidianas, de forma imbricada, sem a necessidade da racionalização do processo. Efetivamente isso significa que, para sair do aspecto de "conceito da moda" para algo que seja aplicado, é necessário um processo de estruturação do campo da sustentabilidade.

Percebe-se, no entanto, que, pela descrição dos respondentes da pesquisa - no geral, mais entre os professores e alunos do curso de Mecatrônica e menos entre os professores e alunos do curso de Processos Ambientais e do projeto de extensão - ainda é distante a ideia de sustentabilidade como prática social. Entende-se que esse processo ainda seja incipiente e que para que aconteça de forma efetiva são necessárias algumas etapas que passam por instituições criadoras de normas, regras e leis capazes de auxiliar no processo de estruturação.

É possível perceber alguns indícios desse processo inicial em determinadas disciplinas de alguns cursos da instituição estudada e na elaboração do projeto pedagógico da instituição, que aborda a preocupação com a sustentabilidade em seus objetivos. No entanto, até o momento, pelas evidências levantadas, essa preocupação é bastante pontual (acontece em disciplinas específicas) e em outras disciplinas simplesmente não se traduz em atividades efetivas e beira o formalismo. 


\section{Análise dos Dados}

Com base nos princípios do paradigma e do modelo condicional/consequencial da grounded theory, desenvolveu-se a análise dos dados com o objetivo de entender o contexto e os processos referentes à formação da noção de sustentabilidade como uma prática social nos casos analisados. Dessa forma, a análise está apresentada na Figura 5. Nesta figura, estão delimitadas as condições, os elementos e as consequências do processo, cuja interação constitui o contexto em análise.

\begin{tabular}{|c|c|}
\hline $\begin{array}{l}\text { Sociedade - } \\
\text { condições }\end{array}$ & $\begin{array}{l}\text { De forma lenta está despertando para as questões relacionadas à sustentabilidade. } \\
\text { Com o desenvolvimento tecnológico acelerado, há escassez de profissionais na área de exatas. }\end{array}$ \\
\hline $\begin{array}{l}\text { IFES - } \\
\text { condições }\end{array}$ & $\begin{array}{l}\text { Tem o foco e a história voltada à área de tecnologia e reconhece no PDI a necessidade de formação } \\
\text { multidisciplinar (formação humana e ambiental). }\end{array}$ \\
\hline \multirow{3}{*}{$\begin{array}{l}\text { Cursos / } \\
\text { extensão - } \\
\text { condições }\end{array}$} & $\begin{array}{l}\text { Mecatrônica } \\
\text { Tem foco técnico: automação de equipamentos e processos manufaturados. Na matriz curricular, há apenas } \\
\text { uma disciplina, denominada Sistemas Integrados de Gestão, que aborda questões relacionadas à } \\
\text { sustentabilidade. Nas ementas das disciplinas técnicas, por ocasião do reconhecimento do curso, foi } \\
\text { incluído, por exigência dos auditores do MEC, o tópico "descarte de resíduos". } \\
\text { Foco: Técnico }\end{array}$ \\
\hline & $\begin{array}{l}\text { Processos Ambientais } \\
\text { É um curso da área de química com ênfase na área de tratamento de resíduos. Na finalidade do curso já se } \\
\text { percebe a tendência à sustentabilidade. } \\
\text { Foco: Meio ambiente }\end{array}$ \\
\hline & $\begin{array}{l}\text { Extensão } \\
\text { Estas atividades estão vinculadas a um mestrado acadêmico, que tem como tema o desenvolvimento } \\
\text { regional. } \\
\text { Esses projetos de extensão versam sobre políticas públicas para populações urbanas, com objetivo de sua } \\
\text { inserção social. Estes projetos são apoiados pelo Programa de Educação Tutorial e Programa de Extensão } \\
\text { (Proext, 2010). } \\
\text { Foco: Responsabilidade social }\end{array}$ \\
\hline \multirow{3}{*}{$\begin{array}{l}\text { Professores - } \\
\text { elementos }\end{array}$} & $\begin{array}{l}\text { Mecatrônica } \\
\text { Ampla formação técnica. } \\
\text { Conceito de sustentabilidade: noções superficiais ligadas ao meio ambiente. Acreditam que as } \\
\text { empresas usam o conceito apenas por moda e marketing. Não consideram o tema importante, já que tudo } \\
\text { parece insustentável. }\end{array}$ \\
\hline & $\begin{array}{l}\text { Processos Ambientais } \\
\text { Formação técnica tradicional, porém com as pós-graduações nas áreas de meio ambiente. Têm experiência } \\
\text { de atuação em comunidades e coordenam projetos de extensão voltados ao meio ambiente. } \\
\text { O empenho em efetivar ações de sustentabilidade está ligado às características pessoais, como } \\
\text { proatividade, capacidade de trabalhar em grupo e resiliência. } \\
\text { Conceito de sustentabilidade: consideram um tema urgente e que é necessário propagar para todas as } \\
\text { pessoas, porém reconhecem que é um processo de conscientização contínuo e demorado. Tendem a } \\
\text { enxergar com ênfase as questões ambientais comparativamente à responsabilidade social e ao } \\
\text { desenvolvimento econômico. }\end{array}$ \\
\hline & $\begin{array}{l}\text { Extensão } \\
\text { Atuou anteriormente em gestão pública, portanto, conhece com profundidade as políticas públicas e os } \\
\text { canais para obter as reivindicações. Tem formação na área de ciências sociais com pós-graduação em } \\
\text { engenharia de produção. } \\
\text { Conceito de sustentabilidade: possui uma noção ampla de sustentabilidade, com ênfase em } \\
\text { responsabilidade social. Essa noção está vinculada a questões práticas, tais como projetos que valorizam as } \\
\text { atividades desenvolvidas pelas pessoas em suas vidas cotidianas. A sustentabilidade para esse professor } \\
\text { também está pautada em crenças e valores pessoais e no trabalho desenvolvido coletivamente, em que os } \\
\text { envolvidos têm objetivos comuns e buscam benefícios para as comunidades de que fazem parte. }\end{array}$ \\
\hline \multirow{3}{*}{$\begin{array}{l}\text { Estudantes - } \\
\text { elementos }\end{array}$} & $\begin{array}{l}\text { Mecatrônica } \\
\text { A tendência de quem escolhe esse curso é de ser mais introvertido e voltado às questões práticas. Estão } \\
\text { focados em passar na disciplina, assim, conceitos subjacentes não são considerados relevantes. } \\
\text { Conceito de sustentabilidade: cada estudante citou, superficialmente, questões de sobrevivência } \\
\text { econômica da empresa, não poluir o meio ambiente e saúde da força de trabalho. }\end{array}$ \\
\hline & $\begin{array}{l}\text { Processos Ambientais } \\
\text { Ao escolherem essa profissão, já são naturalmente sensibilizados para a questão ambiental. } \\
\text { Conceito de sustentabilidade: percebe-se que os alunos, apesar de terem contato com assuntos e } \\
\text { professores que se preocupam com a sustentabilidade, ainda estão no início do processo, ou seja, estão } \\
\text { aprendendo os conceitos relacionados à sustentabilidade e iniciando o processo de conscientização no que } \\
\text { tange à noção de práticas sustentáveis. }\end{array}$ \\
\hline & $\begin{array}{l}\text { Extensão } \\
\text { Os projetos de extensão agregam um grupo multidisciplinar com estudantes das áreas de Sistema de } \\
\text { Informação, Engenharia, Design, Administração, Comunicação Institucional, Radiologia, entre outros. O perfil } \\
\text { dos estudantes que se candidatam e são selecionados pelo coordenador é sensível às questões da } \\
\text { sustentabilidade. } \\
\text { Conceito de sustentabilidade: necessidade de realizar ações hoje que não prejudiquem o futuro de } \\
\text { todos. }\end{array}$ \\
\hline
\end{tabular}


Continuação...

Aulas -

elementos

\section{Mecatrônica}

O foco é no funcionamento dos sistemas, embora sejam abordados conteúdos de gestão de projetos que atuam apenas nos fatores do contexto.

A condição para a aprovação é o funcionamento do sistema. Sob essa premissa e pressão, os estudantes preocupam-se em criar condições para o funcionamento. Não é considerado, por exemplo, como será o destino dos componentes ou a melhor forma de adquirir a matéria-prima. Assim, é enfatizada a solução de problemas imediatos, sem pensamento e consequências de longo prazo.

A função do professor após definir e explicar as especificações é cobrar prazos e tirar dúvidas das equipes.

\section{Processos Ambientais}

A disciplina tem o objetivo de implantar um projeto de educação ambiental aplicado na própria universidade. A interação entre professora e estudantes visa a desenvolver atividades que resultem em educação ambiental com linguagem acessível aos diversos públicos da universidade, entre eles, estudantes, servidores e equipe de serviços gerais.

Os prazos são longos e o projeto prevê o trabalho de no mínimo cinco anos, portanto, várias turmas irão trabalhar. No projeto, os estudantes propõem e executam vários itens como slogans, conteúdos a serem divulgados em sites e redes sociais, apresentação para outros estudantes e servidores, dinâmicas de grupo, entre outras atividades. Isto os obriga a ir além dos conteúdos técnicos previstos no curso, bem como a trabalhar em grupo com estudantes de outros cursos.

\section{Extensão}

Tem foco em projetos de extensão que contemplam trabalhos com a comunidade e análises críticas de filmes e livros. Para organizar e divulgar esta série de atividades, o grupo mantém um site no qual temas relacionados às políticas públicas são veiculados. Os estudantes acompanham o professor nas atividades junto às comunidades e aos órgãos públicos. E a cada ação, são emitidos relatórios.

O coordenador tem a papel de definir as atividades necessárias, porém a forma, quem e quando serão executadas cabe aos estudantes decidir em um processo de trabalho em grupo e de autogestão.

\section{Mecatrônica}

É um curso voltado para o desenvolvimento de um projeto e, além de não se preocupar com questões relacionadas à sustentabilidade, tampouco desenvolve práticas sociais. Alguns alunos mencionam a busca por materiais reciclados, mas isso não se configura como uma prática social, pois não é algo incorporado às suas atividades e práticas diárias, além de ser uma ação incipiente e que não tem uma característica mais abrangente e duradoura de prática social.

Práticas sociais consequências

\section{Processos Ambientais}

Neste curso, alguns professores procuram desenvolver algumas atividades que, apesar de ainda incipientes, podem se configurar como tentativas de desenvolvimento de práticas sociais. No geral, elas aparecem, inicialmente, como práticas pedagógicas que são pensadas e executadas pelos professores que têm uma noção de prática social. A partir do desenvolvimento dessas práticas, ao se tornarem práticas em uso (Orlikowski, 2000), algumas delas se tornam práticas sociais. Isso acontece quando elas começam a fazer parte do dia a dia do estudante e/ou do professor e geram resultados positivos tanto para o estudante, quanto para o professor e para outros atores que têm um relacionamento próximo aos estudantes e aos professores.

\section{Extensão}

Nesse projeto de extensão, são empreendidas ações voltadas para a prática, pautadas em um direcionamento bem estruturado e, principalmente, com o envolvimento de todos. Desde a concepção do projeto há uma preocupação em aproveitar, ao máximo, as competências e habilidades dos envolvidos. Conforme o idealizador do projeto menciona, as tarefas, as decisões e as ações são desenvolvidas com base em um diagnóstico 'de baixo para cima'. Aproveitam-se (e principalmente é dado o devido valor) as habilidades dos participantes e, com isso, percebe-se que o projeto passa a fazer mais sentido para aquele que participa, pois não é algo imposto. Os envolvidos compartilham os mesmos sentidos e significados e trabalham em conjunto em busca de um objetivo comum. Pode-se dizer que o que eles executam são práticas sociais, pois são rotinizadas e trabalhadas em todas as suas atividades cotidianas de forma imbricada. Diante disso, pode-se inferir que a noção de prática social observada neste projeto de extensão se assemelha ao conceito de prática social desenvolvido por Chia e Rasche (2010): a prática social constitui agentes individuais que agem e interagem, na maioria das vezes, espontaneamente e propositalmente de uma forma autorreferencial para superar problemas e obstáculos imediatos sem a necessidade de uma distância teórica, deliberação consciente ou um plano de ação predeterminado. Nessa perspectiva, não há distinção pressuposta, a priori, entre indivíduo e sociedade, não há dualismo entre mente e matéria e não há distância, a priori, entre pensamento e ação: essas questões são consideradas distinções secundárias geradas pelas práticas sociais em si.

\section{Mecatrônica}

É reforçado o foco tecnicista, mantendo-se a visão de mundo limitada e imediata, sem pensar nas consequências para sociedade atual e futura.

\section{Processos Ambientais}

Como o projeto tem que ser aplicado e, mesmo com todos os esforços, os estudantes constatam que a

Estudantes consequências

Estudantes consequências comunidade da universidade apresenta apenas pequenos incrementos de conscientização, os estudantes passam a se questionar sobre vários aspectos: a viabilidade, a real efetividade, se a forma tratada é adequada, o porquê de não conseguirem atingir jovens de perfil tão parecido com o deles, sobre um tema cuja importante, para eles, parece evidente. Portanto, ao final dessa disciplina, os estudantes tornam-se mais críticos pela vivência plena no processo.

Outro aspecto a ser considerados é a dificuldade de traduzir conceitos técnicos para a linguagem leiga. Isso os leva a buscar o desenvolvimento de um processo cognitivo capaz de sensibilizar toda a comunidade.

\section{Extensão}

Pela presença junto à comunidade, tornam-se mais sensibilizados quanto a essas questões. $\mathrm{O}$ trabalho em grupo, com a equipe multidisciplinar e a necessidade de autogestão, os expõe a situações que vão além das previstas nos diversos cursos que estudam e os levam a desenvolver competências adicionais. 
Continuação..

\begin{tabular}{|c|c|}
\hline \multirow{3}{*}{$\begin{array}{l}\text { Professores - } \\
\text { consequências }\end{array}$} & $\begin{array}{l}\text { Mecatrônica } \\
\text { Em relação à inclusão obrigatória do tema "descarte de resíduos", não se sentem motivados a abordar o } \\
\text { assunto, porque, além de não fazer sentido, é apenas uma ação de marketing. Como não foi feita solicitação } \\
\text { oficial sobre a inclusão desse tema ou receberam treinamento, não consideram mandatória a abordagem e } \\
\text { seguem com os conteúdos técnicos. Acreditam que a única forma de motivar os estudantes a se dedicar ao } \\
\text { máximo é exigir o funcionamento do sistema, como condição para a aprovação. Não consideram nenhuma } \\
\text { outra forma de avaliação complementar, porque se supõe que os estudantes não fariam esforço para } \\
\text { cumpri-las. }\end{array}$ \\
\hline & $\begin{array}{l}\text { Processos Ambientais } \\
\text { Têm consciência de que só são possíveis pequenos incrementos à aprendizagem em direção à } \\
\text { sustentabilidade, consequentemente, seguem o projeto mantendo motivação própria e procurando motivar } \\
\text { os estudantes. } \\
\text { Percebem-se solitários nessas atividades pelas questões burocráticas, falta de infraestrutura adequada e } \\
\text { perfil de vários colegas que não reconhecem o valor e a necessidade do projeto. }\end{array}$ \\
\hline & $\begin{array}{l}\text { Extensão } \\
\text { Tem como conceito de extensão o compartilhamento do conhecimento com a sociedade, o qual contrasta } \\
\text { com a visão majoritária da universidade, que é a prestação de serviços. Isso resulta em um trabalho } \\
\text { solitário, pois não consegue motivar seus pares a participar dos projetos. Contudo, conta com a equipe de } \\
\text { bolsistas sintonizados nos mesmos valores, portanto, seus projetos têm se ampliado. } \\
\text { Tem consciência que ao lidar com políticas públicas, vários entraves podem vir a ocorrer. Trata cada um que } \\
\text { aparece e segue respeitando os tempos das comunidades e dos órgãos públicos. Considera essa situação } \\
\text { uma característica inerente ao tipo de projeto que coordena. }\end{array}$ \\
\hline \multirow{3}{*}{$\begin{array}{l}\text { Cursos / } \\
\text { extensão - } \\
\text { consequências }\end{array}$} & $\begin{array}{l}\text { catrônica } \\
\text { rece ser um problema, dado o alto nível de empregabilidade dos egressos. }\end{array}$ \\
\hline & $\begin{array}{l}\text { Processos Ambientais } \\
\text { Os estudantes passam por vivências que os levam a compreender que as pessoas nem sempre consideram } \\
\text { o meio ambiente relevante, que conscientizações levam tempo e que para superar as dificuldades é preciso } \\
\text { persistência. Essas são competências que vão além dos conteúdos técnicos. }\end{array}$ \\
\hline & $\begin{array}{l}\text { Extensão } \\
\text { Além da ampliação das competências dos bolsistas participantes, a existência de projetos de extensão dessa } \\
\text { natureza leva a universidade a se sintonizar com as novas tendências sociais, contribuindo para melhorar a } \\
\text { imagem da instituição. A partir dos diversos conhecimentos e competências desenvolvidas com esses } \\
\text { projetos, foi possível ofertar um mestrado profissional em políticas públicas. }\end{array}$ \\
\hline $\begin{array}{l}\text { IFES - } \\
\text { consequências }\end{array}$ & $\begin{array}{l}\text { Embora esteja enfatizado no PDI, não há uma política institucional ampla e deliberada com vistas a } \\
\text { implantar a sustentabilidade em todos os cursos. } \\
\text { As poucas ações de sustentabilidade são implementadas de forma isolada e focadas apenas nos cursos } \\
\text { correlatos à área. Essas ações são efetivadas por professores cujo perfil pessoal e formação acadêmica os } \\
\text { levaram a considerar o tema relevante para ser abordado de forma persistente com os estudantes. Fazem } \\
\text { isso contornando os entraves burocráticos, da solidão ou da grande quantidade de tempo necessário para } \\
\text { efetivá-las. } \\
\text { Portanto, embora o IFES não tenha uma política deliberada, beneficia-se das açães isoladas dos professores. } \\
\text { Entre os vários benefícios, estão: (1) reforço da imagem do IFES pela associação com um tema de interesse } \\
\text { da sociedade; (2) aumento da capacitação e habilidades dos professores; e (3) implantação de um projeto } \\
\text { que utiliza a força de trabalho dos próprios estudantes. }\end{array}$ \\
\hline & $\begin{array}{l}\text { Levará mais tempo para receber profissionais que consideram a sustentabilidade em suas profissões, } \\
\text { independentemente da área de atuação. }\end{array}$ \\
\hline
\end{tabular}
consequências independentemente da área de atuação.

Figura 5 - Análise dos dados considerando condições, elementos e consequências

Fonte: Elaborada pelos autores.

Diante do quadro apresentado, percebem-se as nuances do processo e do contexto analisado, possibilitando visão ampla da emergência da noção de sustentabilidade como prática social.

\section{Considerações Finais}

O presente estudo foi motivado pela percepção das discussões a respeito de sustentabilidade e da formação de profissionais para seu exercício. Ao mesmo tempo, entendia-se que o exercício profissional sustentável passa por uma conscientização em nível profundo desse conceito, possibilitando trabalhá-lo em todas as ações cotidianas.

Diante disso, entende-se que é necessário que a sustentabilidade seja compreendida como prática social. Isso significa que o conceito de sustentabilidade precisa ser incorporado às rotinas de atividades dos profissionais e que seja reproduzido em contextos de ação e disseminado no contexto profissional de forma recursiva, ultrapassando a dimensão centrada no sujeito, alcançando a dimensão intersubjetiva. O entendimento expresso dessa maneira traz a ideia de que o contexto da formação profissional deve ser comprometido com a construção da sustentabilidade como prática social, propiciando aos estudantes uma formação capaz de fazer a socialização como um processo secundário (Berger \& Luckmann, 2003) dentro dessa noção e a partir dela, em um processo recursivo, trabalhar a sustentabilidade no seu contexto profissional.

Os achados de pesquisa permitem compreender que esse é um processo ainda em construção: enquanto um dos cursos estudados não apresenta o comprometimento com a noção de sustentabilidade, outros dois casos evidenciam uma preocupação com o assunto e isso se traduz em ações que buscam a formação do conceito de sustentabilidade como prática social. No entanto, percebe-se que os estudantes ainda não têm clara essa noção, indicando que a efetivação do conceito em prática social ainda tem um caminho a ser trilhado 
conforme as tendências apontadas pelos especialistas em educação para a sustentabilidade. Outro ponto a ser destacado é que a sociedade precisa incorporar também a sustentabilidade como noção importante, porque sem isso não é possível a disseminação das práticas vinculadas a esse entendimento fora do contexto universitário.

Diante do exposto, entende-se que o conceito de sustentabilidade precisa ser repensado para a formação profissional, comprometendo-se com o desenvolvimento sustentável: antes de ser um conceito técnico, ele deve ser compreendido como um tema específico e transversal. Deve ser tratado de forma a comprometer os profissionais com o desenvolvimento e a prática no cotidiano do desempenho de suas ações.

A partir do pensamento nessa linha, é possível apresentar algumas ideias de estudos futuros: (1) o desenvolvimento de metodologias de ensino-aprendizagem capazes de sistematizar formas de ensino que conduzam à formação de profissionais comprometidos com a sustentabilidade; (2) o delineamento de competências específicas aos profissionais que exercem seu trabalho de forma sustentável; e (3) a verificação de práticas sociais específicas para a formação de profissionais na área de Administração, relacionadas à sustentabilidade.

\section{Notas}

1- Os autores agradecem as contribuições para a reflexão e o aprimoramento dos editores Sr. Diego Coraiola e Sr. André L. M. de Souza Leão, bem como aos dois revisores anônimos pelas críticas e comentários construtivos.

\section{Referências}

Allen-Gil, S., Walker, L., Thomas, G., Shevory, T., \& Elan, S. (2005). Forming a community partnership to enhance education in sustainability. International Journal of Sustainability in Higher Education, 6(4), $392-402$.

Barbieri, J. C. (2011). Gestão ambiental empresarial: conceitos, modelos e instrumentos (3a ed.). São Paulo: Saraiva.

Berger, P. L., \& Luckmann, T. (2003). La construcción social de la realidad. Buenos Aires: Amorrortu editores, 18 a reimpressão.

Blackburn, W. R. (2007). The sustainability handbook: the complete management guide to achieving social, economic and environmental responsibility. Washington, DC: ELI Press.

Carrillo-Hermosilla, J., Gonzalez, P. D. R., \& Könnölä, T. (2009). Eco-Innovation: when sustainability and competitiveness shake hands. New York: Palgrave Macmillan.

Certeau, M. de (1984). The practice of everyday life. California: University of California Press.

Certeau, M. de (1994). A invenção do cotidiano: artes de fazer. Rio de Janeiro: Vozes.

Chia, R., \& Rasche, A. (2010). Epistemological alternatives for researching strategy as practice: building and dwelling worldviews. In D. Golsorkhi, L. Rouleau, D. Seidl, \& E. Vaara (Eds.). Cambridge handbook of strategy as practice. Cambridge: Cambridge University Press.

Comissão Mundial Sobre Meio Ambiente e Desenvolvimento. (1991). Nosso futuro comum (2a ed.). Rio de Janeiro: Editora da Fundação Getúlio Vargas.

Fortuin, I. K. P. J., \& Bush, S. R. (2010). Educating students to cross boundaries between disciplines and cultures and between theory and practice. International Journal of Sustainability in Higher Education, 11(1), 19-35.

Giddens, A. (2003). A constituição da sociedade. São Paulo: Martins Fontes.

Grauerholz, L. (2001). Teaching holistically to achieve deep learning. College Teaching, 49(2), 44-50.

Hart, S. L. (2006). O capitalismo na encruzilhada: as inúmeras oportunidades de negócios na solução dos problemas mais difíceis do mundo. Porto Alegre: Bookman.

Henze, C. (2000). Sustainability in teacher training courses in a sample of German universities. International Journal of Sustainability in Higher Education, 1(3), 280-289.

Johnson, G., Langley, A., Melin, L., \& Whittington, R. (2007). Strategy as practice: research directions and resources. Cambridge: Cambridge University Press.

La Ville, V. de, \& Mounoud, E. (2003). Between discourse and narration: how can strategy be a practice? In B. Czarniawska \& P. Gagliardi. Narratives we organize by. Sweden: John Benjamin Publishing.

La Ville, V. de, \& Mounoud, E. (2006). A narrative view on strategizing and organising: the multiple stories of regional, public yet self-designed, organization. In EGOS Colloquium - European Group for Organizational Studies, 2006. Retrieved from http://www.strategy-as-practice.org

Marschall, R. S., \& Harry, S. P. (2005). Introducing a new business course: global business and sustainability. International Journal of Sustainability in Higher Education, Vol. 6, № 2. 
Meadows, D. H., Meadows, D. L., \& Randers, J. (1992). Beyond the limits: confronting global collapse, envisioning a sustainable future. USA: Chelsea Green Publishing Company.

Orlikowski, W. J. (2000). Using technology and constituting structures: a practice lens for studying technology in organizations. Organization Science, 11(4), 404-428.

Padilha, M. L. de M. L. (2009). Indicadores de desenvolvimento sustentável para o setor têxtil. Tese de doutorado, Universidade de São Paulo - Faculdade de Saúde Pública, São Paulo, SP, Brasil. Disponível: http://www.teses.usp.br/teses/disponiveis/6/6134/tde-09042009-115825/pt-br.php

Sampieri, R. H., Collado, C. F., \& Lucio, P. B. (2006). Metodologia da pesquisa (3a ed.). São Paulo: McGraw-Hill.

Scandelari, V. R. N., \& Cunha, J. C. (2011, setembro). O desempenho ambiental de organizações ambidestras: um levantamento junto a empresas da indústria eletroeletrônica. Anais do Encontro Nacional da Associação Nacional de Pós-Graduação e Pesquisa em Administração, Rio de Janeiro, RJ, Brasil, 35.

Shriberg, M. (2002). Institutional assessment tools for sustainability in higher education. International journal of Sustainability in Higher Education, 3(3), 254-270.

Sipos, Y., Battisti, B., \& Grimm, K. (2008). Achieving transformative sustainability learning: engaging head, hands and heart. International Journal of Sustainability in Higher Education, 9(1), 68-86.

Strauss, A., \& Corbin, J. (2008). Pesquisa qualitativa: técnica e fundamentos para o desenvolvimento da teoria fundamentada (2a ed.). Porto Alegre: Artmed.

Stubbs, W., \& Cocklin, C. (2008). Teaching sustainability to business students: shifting mindsets. International Journal of Sustainability in Higher Education, 9(3), 206-221.

Warburton, K. (2003). Deep learning and education for sustainability. International Journal of Sustainability in Higher Education, 4(1), 44-56.

Weenen, H. (2000). Towards a vision of a sustainable university. International Journal of Sustainability in Higher Education, 1(1), 20-34.

Whittington, R. (2002). The work of strategizing and organizing: for a practice perspective. Strategic organization, 1(1), 117-125.

Whittington, R. (2006). Completing the practice turn in strategy research. Organization Studies, $27(5), 613-634$. Yin, R. K. (2001). Estudo de caso: planejamento e métodos (2ª ed.). Porto Alegre: Bookman. 